\title{
Use of Community Engagement Strategies to Increase Research Participation in Practice-based Research Networks (PBRNs)
}

\author{
William Spears, PhD, Janice Y. Tsoh, PhD, Michael B. Potter, MD, \\ Nancy Weller, DrPH, Anthony E. Brown, MD, MPH, \\ Kimberly Campbell-Voytal, PhD, MSN, Christina M. Getrich, PhD, \\ Andrew L. Sussman, PhD, MCRP, John Pascoe, MD, MPH, and \\ Anne Victoria Neale, $\mathrm{PhD}, \mathrm{MPH}$
}

Purpose: Practice-based research networks (PBRNs) are increasingly encouraged to use community engagement approaches. The extent to which PBRNs engage clinic and community partners in strategies to recruit and retain participants from their local communities (specifically racial/ethnic communities) is the focus of this study.

Methods: The design was a cross-sectional survey of PBRN directors in the United States. Survey respondents indicated whether their research network planned for, implemented, and has capacity for activities that engage clinic and community partners in 7 recommended strategies organized into study phases, called the cycle of trust. The objectives of the national survey were to (1) describe the extent to which PBRNs across the United States routinely implement the strategies recommended for recruiting diverse patient groups and (2) identify factors associated with implementing the recommended strategies.

Results: The survey response rate was $63 \%$. Activities that build trust often are used more with clinic partners than with community partners. PBRNs that adopt engagement strategies when working with clinic and community partners have less difficulty in recruiting diverse populations. Multivariate analysis showed that the targeting racial/ethnic communities for study recruitment, Clinical and Translational Science Award affiliation, and planning to use community engagement strategies were independent correlates of PBRN implementation of the recommended strategies.

Conclusion: PBRNs that successfully engage racial/ethnic communities as research partners use community engagement strategies. New commitments are needed to support PBRN researchers in developing relationships with the communities in which their patients live. Stable PBRN infrastructure funding that appreciates the value of maintaining community engagement between funded studies is critical to the research enterprise that values translating research findings into generalizable care models for patients in the community. ( $\mathrm{J}$ Am Board Fam Med 2014;27:763-771.)

Keywords: Patient Recruitment, Practice-based Research, Primary Health Care

In recent years, policymakers and researchers have expressed concern that the medical research system

This article was externally peer reviewed.

Submitted 10 February 2014; revised 30 July 2014; accepted 1 August 2014.

From Departments of Pediatrics (JP) and Community Health (WS), Boonshoft School of Medicine, Wright State University, Dayton, OH; Department of Psychiatry (JYT), University of California, San Francisco; Department of Family and Community Medicine (MBP), School of Medicine, University of California, San Francisco; Department of Nursing Systems, School of Nursing, University of Texas Health Science Center, Houston (NW); Department of Family and Community Medicine, Baylor College of Medicine, Houston, produces new knowledge that may not be incorporated effectively into clinical practice. ${ }^{1,2}$ Acquisition of much of the evidence base of health care

TX (AEB); Department of Family Medicine and Public Health Sciences, Wayne State University, Detroit, MI (KC-V, AVN); Department of Anthropology, University of Maryland, College Park (CMG); and Department of Family and Community Medicine, University of New Mexico, Albuquerque (ALS).

Funding: The study was funded by the National Institutes of Health National Institute for Minority Health and Health Disparities (RC1 MD004692; A.V. Neale, Principal Investigator). This project also was supported by the National Center for Advancing Translational Sciences, National Institutes of Health (through UCSF-CTSI grant no. UL1 TR000004). 
through clinical research conducted in tertiary care academic health centers is one barrier to the translation of research into practice. ${ }^{3}$ This raises concerns about the external validity (generalizability) of findings, in part because the patients treated in such health centers represent fewer than 1 in 1000 patients being treated in the health care system. ${ }^{4,5}$ Thus, to improve the health of the nation, research must include representative samples of the majority who receive health care outside of academic health centers.

Research focusing on health conditions without considering the social, cultural, ethnic, and geographic identity of study participants may not be easily applied to clinical problems and the care of diverse patients in community settings. ${ }^{6-8}$ Practice-based research (PBR) is a model that mixes scientific inquiry and community engagement with several key advantages for applying new medical knowledge into clinical practice, including an emphasis on engaging clinical teams and their patients to formulate research questions, which then are studied in practice settings. PBR also has the potential to address the challenge of effectively integrating new knowledge into primary care delivery settings. The practice engagement strategy may increase the uptake of study findings; that is, participating clinical teams are more likely to use these results in their practice. Results obtained from these settings may be more broadly applicable to community-based clinical settings and the patients they serve. This, in turn, makes the findings more immediately relevant, adoptable, and sustainable than results obtained in academic settings. ${ }^{2}$

Increasingly, PBR networks (PBRNs) are recognized vehicles for building the evidence base of primary care by conducting research in community-based settings. ${ }^{3}$ Patient-centered outcomes research $^{9,10}$ is another recent emphasis that prioritizes community engagement and provides an avenue for primary care researchers to bridge the chasm between recommended care and improved health. ${ }^{3}$ Use of rigorous research methods ensures

Conflict of interest: AVN is Deputy Editor of the $7 A B F M$. She was not involved in the editorial decisions for this paper.

Disclaimer: The contents of this publication are solely the responsibility of the authors and do not necessarily represent the official views of the NIH.

Corresponding author: Anne V. Neale, PhD, MPH, Department of Family Medicine, Wayne State University, 101 E. Alexandrine, Detroit, MI 48201 (E-mail: vneale@med.wayne.edu). the findings will be relevant to the communities served by PBRNs, a diverse mix of practices collaborating to increase research productivity and improve the external validity of findings. ${ }^{9-11}$ Yet the evidence indicates that, until the recent past, few PBRNs routinely use community engagement research strategies. ${ }^{6-8}$

The Clinical Translation Science Award (CTSA) program (www.ctsacentral.org/) supports a national consortium of medical research institutions working to improve methods for conducting clinical and translational research. The CTSA program requires community engagement to carry translational research into clinical practice. ${ }^{11}$ The goals of the CTSA program provide the opportunity for PBRNs to centrally support initiatives to increase the implementation of new knowledge in community-based clinical practices. ${ }^{3,8}$ Westfall et $\mathrm{al}^{7}$ argue that PBR itself is community engagement. Although some PBRNs have successful partnerships with CTSA programs, others continue the important work of population heath management or use practice facilitation strategies to improve care management. ${ }^{2}$

This article reports the findings of a national survey of PBRN directors, the objectives of which were to explore the extent to which PBRNs are prepared to implement approaches that engage community partners and to identify correlates of the implementation of such community engagement approaches. This article presents the results of the quantitative component of a mixed methods study and is a continuation of previously published research that established a cycle of trust for recruiting and retaining racial and ethnically diverse populations into medical research studies. ${ }^{12}$ The cycle of trust emphasizes the importance of developing and sustaining relationships before the study, during study recruitment and conduct, and after study completion. Synthesizing the data from focus groups and key informant interviews resulted in 7 recommended strategies for recruiting and retaining diverse communities in research. ${ }^{12}$ A national survey of PBRN directors (reported here) was conducted to learn about experience with these community engagement strategies.

\section{Methods}

A cross-sectional, self-report survey of PBRN directors in the United States was developed to learn 
about the activities and strategies that PBRNs use to recruit and retain participants from the communities (specifically racial/ethnic communities) in which they work. The objectives of the national survey were to (1) describe the extent to which PBRNs across the United States routinely implement strategies recommended for recruiting diverse patient groups and (2) identify factors associated with implementing those recommended strategies. Research ethics approval was provided by the Wayne State University Institutional Review Board (protocol no. 0908007457).

Investigators from 5 of the 8 PBRN member organizations of the Primary Care Multi-ethnic Network (PRIME Net) PBRN consortium conducted the survey; the participating PBRNs were the MetroNet, Research Involving Outpatient Settings Network, San Francisco Bay Area Collaborative Research Network, Southwestern Ohio Ambulatory Research Network, and Southern Primary-care Urban Research Network). The PRIME Net consortium shares an interest in reducing health disparities in minority, vulnerable, and underserved populations (www.prime-netconsortium.org/).

\section{Survey Development}

The 51-item survey instrument was developed in a collaborative effort by a 5 -member research team from the 5 collaborating PBRNs. Initial drafts of the survey were reviewed and pilot tested by 10 additional individuals belonging to these PBRNs (1 to 3 participants from each of the 5 PBRNs) who were not part of the research team.

\section{Survey Administration}

Survey management was subcontracted to the PBRN Resource Center (http://pbrn.ahrq.gov/ resource-center). The survey questionnaire was administered using Checkbox, a web-based survey tool (www.checkbox.com). The Resource Center invited the directors of the 122 primary care PBRNs active in the 2011 PBRN registry to participate in the survey. Nonresponding directors received follow-up reminder invitations at 2 weeks and 4 weeks following the initial invitation. Respondents were offered a $\$ 50$ gift card for completing the survey.

\section{Survey Questions \\ PBRN Experiences With Community Engagement \\ Strategies}

Respondents were asked to describe their ability to plan and implement and their capacity to perform each of 11 activities for recruiting and retaining participants in primary care research. The $11 \mathrm{ac}-$ tivities were derived from the 7 strategies recommended to create a cycle of trust for recruiting and retaining racial and ethnically diverse populations into medical research studies based on a previous qualitative formative research. ${ }^{12}$ Table 1 lists the survey items and their corresponding strategies supporting the cycle of trust. ${ }^{12}$

\section{PBRN Characteristics}

Respondents also were asked to provide information about their PBRN, including the year the PBRN was established; the patient populations served by member practices (rural only, urban only, both rural and urban); and any racial/ethnic communities specifically targeted for research in the previous 5 years. PBRN research productivity was assessed by the number of PBRN publications and the number of grants awarded in the past 5 years.

Experience recruiting and retaining diverse populations was assessed by 2 survey questions: "How difficult is it for your PBRN to recruit from diverse racial/ethnic communities for research?" and "How difficult is it to retain participants from diverse racial/ethnic communities through the duration of the research project?"

Additional demographic data, obtained with permission from the 2011 respondents of the PBRN Resource Center's annual registry survey, included PBRN affiliations with universities and with funded CTSA programs; the number/types of special populations specifically targeted; and PBRN affiliation with a community advisory board.

\section{Respondent Characteristics}

One person per PBRN responded to the survey. Although the survey invitations were sent to PBRN directors, these administrators were permitted to delegate survey completion to another member. Thus, respondents were asked to indicate their position (PBRN director/codirector; community coordinator/ liaison; director of research; research investigator/coinvestigator; or other) and years in their current position at the PBRN. 
Table 1. PRIME Net Cycle of Trust Recommended Strategies ${ }^{12}$ and Corresponding Survey Items

\begin{tabular}{|c|c|}
\hline $\begin{array}{l}\text { Cycle of Trust: Study } \\
\text { Phase/Strategies }\end{array}$ & Survey Items* \\
\hline \multicolumn{2}{|l|}{ Before the study } \\
\hline $\begin{array}{l}\text { Strategy 1: Trust with targeted } \\
\text { partners }\end{array}$ & $\begin{array}{l}\text { 1. Build relationships with community partner based on mutual trust } \\
\text { 2. Build relationships with practice/clinic partners based on mutual trust }\end{array}$ \\
\hline $\begin{array}{l}\text { Strategy 2: Relevant topic and } \\
\text { feasible study design }\end{array}$ & $\begin{array}{l}\text { 3. Collaborate with community partners to determine research questions and protocols } \\
\text { 4. Choose a feasible design that places minimal burden on the clinic and its workflow }\end{array}$ \\
\hline \multicolumn{2}{|l|}{ Throughout the study } \\
\hline $\begin{array}{l}\text { Strategy 3: A competent research } \\
\text { team }\end{array}$ & $\begin{array}{l}\text { 5. Include practice/clinic partners in the research team to ensure understanding of the } \\
\text { clinic context } \\
\text { 6. Involve culturally and linguistically competent community partners on the research } \\
\text { team (eg, bilingual/bicultural) and in the community, emphasizing familiarity with } \\
\text { cultural norms along sex and class lines and other aspects of social identity }\end{array}$ \\
\hline \multicolumn{2}{|l|}{ During the study } \\
\hline $\begin{array}{l}\text { Strategy 4: Tailored recruitment } \\
\text { strategies }\end{array}$ & $\begin{array}{l}\text { 7. Create recruitment strategies tailored to specific racial/ethnic community needs (eg, } \\
\text { arranging transportation, accessing local media, addressing citizenship status } \\
\text { concerns) }\end{array}$ \\
\hline $\begin{array}{l}\text { Strategy 5: Study } \\
\text { implementation }\end{array}$ & $\begin{array}{l}\text { 8. Identify a person with knowledge of the study to ensure that practice/clinic partners } \\
\text { have a contact for study-related problems }\end{array}$ \\
\hline $\begin{array}{l}\text { Strategy 6: Tailored retention } \\
\text { strategies }\end{array}$ & $\begin{array}{l}\text { 9. Use appropriately timed personal contacts (eg, culturally appropriate thank you cards } \\
\text { for participation) and/or token material incentives (eg, gift cards) to encourage } \\
\text { participants to complete study activities }\end{array}$ \\
\hline \multicolumn{2}{|l|}{ After study completion } \\
\hline $\begin{array}{l}\text { Strategy } 7 \text { : Closing the loop and } \\
\text { sowing the seeds of future } \\
\text { research projects }\end{array}$ & $\begin{array}{l}\text { 10. Customize reporting of study results to the interests of practice/community partners } \\
\text { 11. Involve clinic/community partners in presenting research results to scientific and/or } \\
\text { public audiences }\end{array}$ \\
\hline
\end{tabular}

\section{Statistical Analyses}

Descriptive statistics, including mean scores, standard deviations, and percentages, were calculated for all variables. Eight respondents consistently did not respond to questions about working with community partners. We therefore assumed that these PBRNs perform research that does not regularly engage with communities, and they were dropped from the analysis. For the remaining PBRNs, the values for "do not know," "not applicable," or "no response" were consistent with "never" across all items; these values were recoded as "never." Cycle of trust scales were created for planning, implementation, and capacity to perform using the 11 activity questions. Responses then were summed across all 11 community engagement activities for each experience, with scale scores ranging from 11 to 55. High scores indicated high frequency of planning or implementation or perceived high capacity to perform accordingly. Cronbach $\alpha$ was used to evaluate the planning, implementation, and capacity to perform cycle of trust scales for internal consistency; $\alpha$ values for all scales were acceptable (Table 2).

Table 2. Practice-based Research Network Experience Associated With Community Engagement Activities

\begin{tabular}{lccc}
\hline Cycle of Trust Scale* & Responses (n) & Mean (SD) & Cronbach $\alpha$ \\
\hline Planning scale: "How often does your network plan each activity?" & 68 & $42.1(6.2)$ & 0.70 \\
Implementation scale: "How often does your network implement each activity?" & 68 & $40.0(6.2)$ & 0.75 \\
Capacity scale: "Rate your network's capacity to perform each activity." & 68 & $38.5(7.6)$ & 0.84 \\
\hline
\end{tabular}

*Response options: For each activity, respondents were asked (a) how often they plan for the activity (never, rarely, sometimes, usually, or always); (b) how often they implement the activity in their research studies (never, rarely, sometimes, usually, or always); and (c) to assess the capacity of their practice-based research network to perform each activity (very low, low, medium, high, or very high). $\mathrm{SD}$, standard deviation. 
Table 3. Practice-based Research Network (PBRN) Characteristics, Reported Difficulty Recruiting and

Retaining a Diverse Patient Population in Research, and Experience With Community Engagement

Strategies $(\mathrm{N}=68)$

\begin{tabular}{lll}
\hline PBRN Characteristics & No. & $\%$ \\
\hline PBRN age (years) & & \\
$\quad<5$ & 17 & 25.0 \\
$5-10$ & 23 & 33.8 \\
$\geq 10$ & 28 & 41.2
\end{tabular}

How many publications does your PBRN have? (n)

0 (newly established)

$1-3$

$4-10$

$>10$

How many grants does your PBRN have? (n)

0 (newly started, no extramural grants)

$1-3$

$4-10$

$>10$

Geographic population served

Urban only

Rural only

Both rural and urban

Racial communities specifically targeted for research in the past 5 years

\begin{tabular}{|c|c|}
\hline None & 12 \\
\hline Black or African American & 39 \\
\hline Hispanic or Latino & 38 \\
\hline Asian & 10 \\
\hline Some other race/ethnicity & 17 \\
\hline \multicolumn{2}{|c|}{$\begin{array}{l}\text { How difficult is it to recruit from } \\
\text { diverse racial/ethnic } \\
\text { communities? }\end{array}$} \\
\hline Not difficult & 13 \\
\hline Somewhat difficult & 26 \\
\hline Difficult & 12 \\
\hline Very difficult & 12 \\
\hline Don't know/not applicable & 5 \\
\hline \multicolumn{2}{|l|}{$\begin{array}{l}\text { How difficult is it to retain } \\
\text { participants from diverse } \\
\text { racial/ethnic communities } \\
\text { through the duration of the } \\
\text { research project? }\end{array}$} \\
\hline Not difficult & 9 \\
\hline Somewhat difficult & 32 \\
\hline Difficult & 8 \\
\hline Very difficult & 7 \\
\hline Don't know/not applicable & 12 \\
\hline
\end{tabular}

Continued
Table 3. Continued

\begin{tabular}{lcc}
\hline PBRN Characteristics & No. & $\%$ \\
\hline $\begin{array}{l}\text { Special populations specifically } \\
\text { targeted for research }\end{array}$ & & \\
$\quad$ participation* & & \\
None & 15 & 22.1 \\
Rural & 26 & 38.2 \\
Inner city & 27 & 39.7 \\
Low income & 36 & 52.9 \\
Minority & 36 & 52.9 \\
$\quad$ Underserved populations & 39 & 57.4 \\
$\quad$ Other (urban, LGBT, seniors, & 7 & 10.3 \\
$\quad$ children) & & \\
PBRN has a community advisory & 20 & 29.4 \\
$\quad$ board & & \\
PBRN is affiliated with a & 37 & 54.4 \\
$\quad$ university† & & \\
PBRN is affiliated with a Clinical & 44 & 64.7 \\
$\quad$ Translational Science Award $\dagger$ & & \\
\hline
\end{tabular}

${ }^{*}$ Response categories are not mutually exclusive.

†Data obtained from the 2011 Agency for Health care Research and Quality PBRN Resource Center Registry; all other data were obtained from the PRIME Net Survey of PBRN directors.

To evaluate associations between the independent variables (PBRN characteristics, experience in planning community engagement strategies, and perceived capacity to perform such activities) and implementation of the recommended cycle of trust strategies, univariate generalized linear regression analyses were conducted for each independent variable using implementation of community engagement strategies as the dependent variable. Candidate variables were selected for inclusion as independent predictors in multivariate models when the bivariate associations attained a $P$ value $<.20$. Using a lower inclusion threshold allowed for the possibility that variables not significant at the bivariate level may make a contribution in multivariate analysis.

Multivariate models were conducted with implementation of community engagement strategies as the outcome measure. The first model consisted of only PBRN characteristics. A final multivariate regression model consisting of all the selected variables was used to determine the impact of planning and perceived capacity to perform community engagement strategies moderated by PBRN characteristics and implementation of community engagement strategies.

The multiple regression models were compared by change in $R^{2}$ and $F$ statistics to identify signifi- 
Figure 1. Proportions of practice-based research networks reporting consistent ("always" or "usually") implementation of community engagement strategies

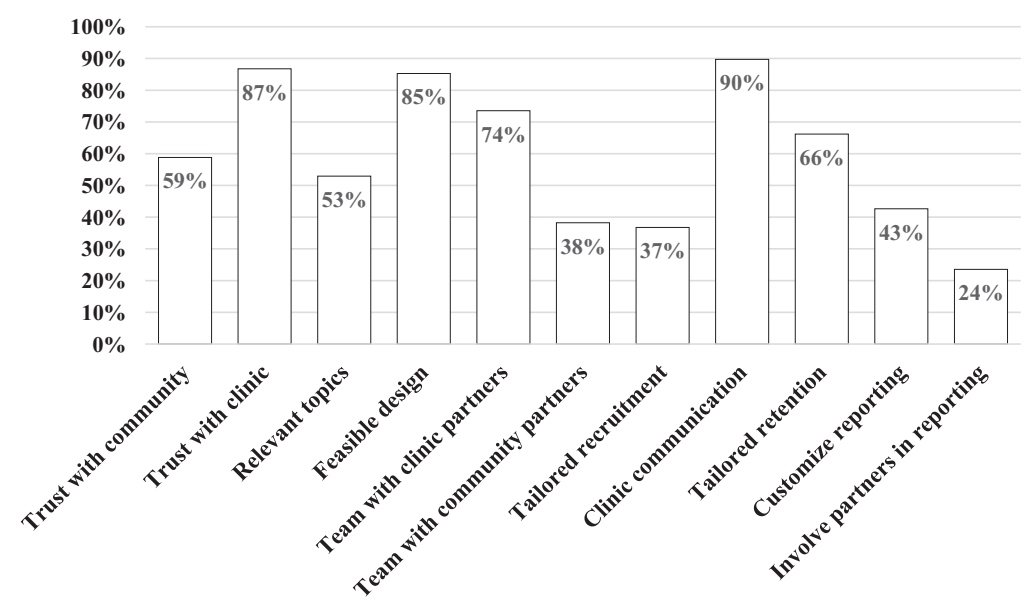

cant correlates of implementation. Statistical significance was set at $P<.05$. The statistical analyses were performed using IBM SPSS Statistics for Windows version 21.0 (IBM, Armonk, NY).

\section{Results}

Representatives from 76 PBRNs completed the online survey between August and November 2011 (63\% response rate); $95 \%$ of respondents comprised PBRN directors/codirectors, community coordinators/liaisons, or directors of research. Eight PBRNs providing responses that suggested their networks were not engaged with community partners were not included in the analysis. Table 3 describes the characteristics of PBRNs. A majority of responding PBRNs were founded more than 5 years before the survey. Most PBRNs had been fairly successful in publishing research articles: $39 \%$ reported publication of $>10$ articles, and $32 \%$ had published between 3 and 10 articles. A majority had received grants in the past 5 years: $35 \%$ obtained funding for $>10$ grants, and $29 \%$ had received between 3 and 10 grant awards.

Of PBRN respondents, $65 \%$ reported an affiliation with a CTSA-funded project, 54\% had a university affiliation, and 29\% reported their PBRN had a community advisory board. While the majority (90\%) of PBRNs included urban practices in their network, $38 \%$ indicated that they target rural populations.

Most (82\%) of the PBRNs recruit racial/ethnic minority populations for research projects. More than half indicated they specifically sought research participants from underserved groups, including low income. One-third indicated it was "difficult" or "very difficult" to recruit racial and ethnic minorities for research projects. One in 5 reported it was "difficult" or "very difficult" to retain diverse participants in research.

\section{PBRNs' Current Practice of Community Engagement Strategies}

Figure 1 shows the proportion of PBRNs that reported consistent implementation of community engagement strategies. The most frequently practiced strategies were activities with clinic partners, including clinic communication (90\%), building trust with a clinic (87\%), and generating a feasible study design in collaboration with clinic partners $(85 \%)$. The strategies involving community partners implemented least often were involving community partners on research teams (38\%); using tailored recruitment strategies (37\%); and involving partners in dissemination of research findings (24\%).

\section{Bivariate Analyses}

Table 4 shows univariate regression coefficients between each independent variable and implementation. Targeting multiple racial communities and special populations (such as low income or underserved) for research was positively associated with implementation of the community engagement strategies. Experiencing higher levels of difficulty recruiting from diverse racial/ethnic communities was associated with lower implementation of 
Table 4. Univariate Regression Coefficient Estimates Between Practice-based Research Network (PBRN) Characteristics, Research Experiences, and Community Engagement Strategy Implementation $(\mathrm{N}=68)$

\begin{tabular}{|c|c|}
\hline PBRN Characteristics & $\beta$ \\
\hline \multicolumn{2}{|l|}{ PBRN age (years) } \\
\hline$<5$ & -0.89 \\
\hline $5-10$ & -0.40 \\
\hline$\geq 10$ & Reference \\
\hline Number of publications & 0.21 \\
\hline Number of grants & -0.34 \\
\hline \multicolumn{2}{|l|}{ Geographic population served } \\
\hline Urban only & -2.11 \\
\hline Rural only & 1.27 \\
\hline Both rural and urban & Reference \\
\hline \multicolumn{2}{|l|}{$\begin{array}{l}\text { Racial communities specifically } \\
\text { targeted for research in the past } \\
5 \text { years* }\end{array}$} \\
\hline $\begin{array}{l}\text { Multiple racial/ethnic } \\
\text { communities }\end{array}$ & $3.41 \dagger$ \\
\hline Single community & $2.63 \dagger$ \\
\hline None & Reference \\
\hline \multicolumn{2}{|l|}{$\begin{array}{l}\text { How difficult is it to recruit from } \\
\text { diverse racial/ethnic } \\
\text { communities for research? }\end{array}$} \\
\hline Difficult or very difficult & $-3.57 \dagger$ \\
\hline Don't know/not applicable & -3.09 \\
\hline Not or somewhat difficult & Reference \\
\hline \multicolumn{2}{|l|}{$\begin{array}{l}\text { How difficult is it to retain } \\
\text { participants from diverse racial/ } \\
\text { ethnic communities through } \\
\text { the duration of the research } \\
\text { project? }\end{array}$} \\
\hline Difficult or very difficult & $-3.39 \dagger$ \\
\hline Don't know/not applicable & $-4.75 \dagger$ \\
\hline Not or somewhat difficult & Reference \\
\hline $\begin{array}{l}\text { Number of special populations } \\
\text { specifically targeted }\end{array}$ & $1.75 \dagger$ \\
\hline $\begin{array}{l}\text { PBRN has a community advisory } \\
\text { board }\end{array}$ & $3.19 \dagger$ \\
\hline PBRN is affiliated with a university ${ }^{\ddagger}$ & -0.59 \\
\hline $\begin{array}{l}\text { BPRN is affiliated with a Clinical } \\
\text { Translational Science Award* }\end{array}$ & $2.77 \dagger$ \\
\hline Planning scale ${ }^{\S}$ & $0.80 \dagger$ \\
\hline Capacity scale $\|$ & $0.55 \dagger$ \\
\hline
\end{tabular}

*Response categories are not mutually exclusive. $\dagger P<.20$ is the criteria used for inclusion in multivariate analysis. ${ }^{\ddagger}$ Data obtained from the 2011 Agency for Health care Research and Quality PBRN Resource Center Registry; all other data were obtained from the PRIME Net Survey of PBRN directors. ${ }^{\S}$ How often does your network plan each activity?

\|Rate your network's capacity to perform each activity.

the community engagement strategies. The frequency with which PBRNs plan to use the community engagement strategies and their self-per- ceived capacity to perform these community engagement strategies were positively associated with their implementation within PBRN research projects.

\section{Multivariate Analyses}

Guided by the bivariate regression results, 6 independent variables were included in the model: racial/ethnic communities targeted, difficulty recruiting participants, difficulty retaining participants in research, number of special populations targeted, community advisory board, and CTSA affiliation. Table 5 shows 2 models for implementation of community engagement strategies and the associated changes in the $R^{2}$ statistic. Before adding the scales "plan to use strategies" and "capacity to perform the strategies" to the model as covariates, "multiple racial/ethnic communities targeted" and "affiliation with a CTSA" were positively associated with implementation (Table 5, model 1). When both the "plan to use strategies" and "capacity to perform strategies" scales were included in the multivariate model, "racial/ethnic communities targeted," "affiliated with a CTSA," and "plan to use strategies" were independent correlates to implementation (Table 5, model 2).

\section{Discussion}

The best predictors of implementing strategies to enhance recruitment/retention seem to be knowledge of the need to engage a clinic and inclusion of community partners in the research process (planning). PBRNs are aware of and value community engagement strategies yet often lack the resources needed to sustain these strategies. Some authors advocate that essential components of community involvement in research are shared decision making, developing appropriate research priorities, cultural competence, and building and maintaining trust between the community and researchers. $^{7,12,13,15-18}$ To implement these components in a sustainable fashion, the infrastructure barriers that come from the piecemeal or study-specific funding of most PBRNs need to be overcome.

Many PBRN researchers embrace participatory research strategies used in social science to engage the broader community in the research process. $^{2,3,6-8,12,13,15,16,19}$ Two earlier reports, however, indicated little evidence of community member involvement in network research operations. ${ }^{3,8}$ 
Table 5. Multiple linear regression models of correlates for Implementation of Recommended Community Engagement Strategies

\begin{tabular}{|c|c|c|c|c|}
\hline \multirow[b]{2}{*}{ PBRN Characteristics } & \multicolumn{2}{|c|}{ Model 1* } & \multicolumn{2}{|c|}{ Model 2† } \\
\hline & $\beta$ & SE & $\beta$ & SE \\
\hline \multicolumn{5}{|l|}{ Retention difficulty } \\
\hline Difficult & -3.60 & 2.24 & -1.32 & 1.30 \\
\hline Don't know/not applicable & -4.33 & 3.01 & -2.66 & 1.86 \\
\hline \multicolumn{5}{|l|}{ Minimal (reference) } \\
\hline \multicolumn{5}{|l|}{ Recruitment difficulty } \\
\hline Difficult & -1.64 & 1.81 & -0.10 & 1.02 \\
\hline \multicolumn{5}{|l|}{ Minimal (reference) } \\
\hline \multicolumn{5}{|l|}{ Racial/ethnic communities targeted } \\
\hline Single community & 2.77 & 2.56 & $3.15^{\ddagger}$ & 1.46 \\
\hline Multiple & $4.85^{\ddagger}$ & 2.23 & $3.43^{\ddagger}$ & 1.28 \\
\hline \multicolumn{5}{|l|}{ None (reference) } \\
\hline Number of special populations targeted for research participation & -0.27 & 0.83 & -0.42 & 0.49 \\
\hline PBRN has a community advisory board & 2.30 & 2.16 & 1.14 & 1.22 \\
\hline PBRN affiliated with a Clinical Translational Science Award & $6.49^{\ddagger}$ & 1.91 & $2.78^{\ddagger}$ & 1.22 \\
\hline Planning scale ${ }^{\S}$ & \multicolumn{2}{|c|}{ Not included } & $0.47^{\ddagger}$ & 0.11 \\
\hline Capacity scale\| & \multicolumn{2}{|c|}{ Not included } & 0.16 & 0.09 \\
\hline
\end{tabular}

${ }^{*} R^{2}=0.49$.

†Change in $R^{2}$ from model $1=0.36(P<.001)$.

${ }^{\ddagger} P<.05$.

${ }^{\S}$ How often does your network plan each activity?

$\|$ Rate your network's capacity to perform each activity.

PBRN, practice-based research network.

For example, in 2006 Westfall et $\mathrm{al}^{6}$ found that community members were included on network boards in fewer than $25 \%$ of PBRNs, and few of these provided review and feedback about research findings. ${ }^{6}$ By comparison, $30 \%$ of our respondents reported a community advisory board, and $25 \%$ involved partners in disseminating research findings, perhaps suggesting modest improvement in engaging community partners in dissemination activities. The recommended strategies seem to be more frequently implemented with clinical partners and less with the community; this is not surprising given the expense of implementing community engagement strategies. This seems to support the need for an improved community engagement infrastructure.

\section{Limitations}

Consideration of the study limitations is important. The survey did not capture the landscape of all PBRN work (eg, care delivery process improvements or population health management) nor the nature of the PBRN/CTSA collaboration. The self-reported data from one respondent per PBRN may not represent the range of perspectives in the network. The 3 cycle of trust scales (planning, implementation, and capacity to perform), though not collinear, were highly correlated, contributing to the high proportion of variance explained. Furthermore, there may have been other important unmeasured confounders. Although we achieved a response rate of $63 \%$, the study results might differ with a larger participation rate; it is possible that the most community-engaged PBRNs were more motivated to participate. Among the respondents, $65 \%$ had some affiliation with a CTSA; this is higher than the $50 \%$ reported by the PBRN Registry in $2011 .^{20}$ More detail of PBRN involvement in CTSA activities could help explain the role CTSAs play in the use of community engagement strategies. Further research is still needed to identify other factors that support the use of community engagement strategies.

\section{Conclusions}

New efforts are needed to support PBRNs in developing and sustaining relationships with the com- 
munities in which their patients live. Stable PBRN infrastructure funding that acknowledges the value of maintaining community engagement in between funded studies is critical to translating research findings into generalizable care models for patients in the community. This study suggests that PBRNs that developed the capacity to perform the recommended engagement strategies seem to have done so successfully. This is important new evidence of the efficacy of the recommended community engagement strategies comprising the cycle of trust. ${ }^{12}$ Similarly, the National Institutes of Health Director's Council of Public Representatives endorsed strategies that (1) treat the public as a partner in the research process; (2) share research results with the community; (3) view research as part of a long-term commitment to the community; and (4) value community partnership in research. ${ }^{15}$ This study adds to the mounting evidence that community engagement is an important strategy for improving health research, the benefits of which include increased recruitment/retention, greater diversity of participants, more representative cohorts, and increased trust between community members and researchers. $^{21}$

\section{References}

1. Glasgow RE, Emmons KM. How can we increase translation of research into practice? Types of evidence needed. Annu Rev Public Health 2007;28: 413-33.

2. Mold JW, Peterson KA. Primary care practice-based research networks: working at the interface between research and quality improvement. Ann Fam Med 2005;3(Suppl 1):S12-20.

3. Westfall JM, Mold J, Fagnan L. Practice-based research-"Blue Highways" on the NIH roadmap. JAMA 2007;297:403-6.

4. White KL, Williams TF, Greenberg BG. The ecology of medical care. N Engl J Med 1961;265:885-92.

5. Green LA, Fryer GE, Yawn BP, Lanier D, Dovey SM. The ecology of medical care revisited. N Engl J Med 2001;344:2021-5.

6. Westfall JM, VanVorst RF, Main DS, Herbert C. Community-based participatory research in practice-based research networks. Ann Fam Med 2006; 4:8-14.

7. Westfall JM, Fagnan LJ, Handley M, et al. Practicebased research is community engagement. J Am Board Fam Med 2009;22:423-7.

8. Williams RL, Shelley BM, Sussman AL. The marriage of community-based participatory research and practice-based research networks: can it work? A
Research Involving Outpatient Settings Network (RIOS Net) study. J Am Board Fam Med 2009;22: 428-35.

9. Westfall JM, Nearing K, Felzien M, et al. Researching together: a CTSA partnership of academicians and communities for translation. Clin Translat Sci 2013;6:356-62.

10. Concannon TW, Meissner P, Grunbaum JA, et al. A new taxonomy for stakeholder engagement in patient-centered outcomes research. J Gen Intern Med 2012;27:985-91.

11. Research. Clinical and translational science. Bethesda (MD): National Center for Advancing Translational Sciences. Available from: http:// www.ncats.nih.gov/research/cts/cts.html. Accessed July 15, 2014.

12. Getrich CM, Sussman AL, Campbell-Voytal K, et al. Cultivating a cycle of trust with diverse communities in practice-based research: a report from PRIME Net. Ann Fam Med 2013;11:550-8.

13. Jones L, Wells K. Strategies for academic and clinician engagement in community-participatory partnered research. JAMA 2007;297:407-10.

14. Carter-Edwards L, Cook JL, McDonald MA, Weaver SM, Chukwuka K, Eder M. Report on CTSA consortium use of the community engagement consultant service. Clin Transl Sci 2012;6: 34-9.

15. Clinical and Translational Science Awards. Community Engagement Key Function Committee. Available from: https://www.ctsacentral.org/committee/ community-engagement. Accessed July 15, 2014.

16. Macaulay AC. Promoting participatory research by family physicians. Ann Fam Med 2007;5:557-60.

17. Williams RL, Rhyne RL. No longer simply a practice-based research network (PBRN) health improvement networks. J Am Board Fam Med 2011; 24:485-8.

18. Davis MM, Keller S, DeVoe JE, Cohen DJ. Characteristics and lessons learned from practice-based research networks (PBRNs) in the United States. J Healthc Leadersh 2012;4:107-16.

19. Knox LM, Aspy CB. Quality improvement as a tool for translating evidence based interventions into practice: what the youth violence prevention community can learn from healthcare. Am J Community Psychol 2011;48:56-64.

20. Peterson KA, Lipman PD, Lange CJ, Cohen RA, Durako S. Supporting better science in primary care: a description of practice-based research networks (PBRNs) in 2011. J Am Board Fam Med 2013;25: 565-71.

21. Eder M, Carter-Edwards L, Hurd TC, Rumala BB, Wallerstein N. A logic model for community engagement within the clinical and translational science awards consortium: can we measure what we model? Acad Med 2013;88:1430-6. 